Sharif University of Technology
Scientia Iranica

\title{
Control and performance assessment of variable rotor resistance-based wind turbines regarding aerodynamic power fluctuations
}

\author{
M. Rahimi* \\ Department of Electrical and Computer Engineering, University of Kashan, Kashan, Iran. \\ Received 14 April 2016; received in revised form 27 August 2016; accepted 26 September 2016
}

\author{
KEYWORDS \\ Aerodynamic torque \\ fluctuations; \\ Limited variable speed \\ wind turbine; \\ Power-slip curve; \\ Shaft stiffness; \\ Wind turbine \\ with variable rotor \\ resistance.
}

\begin{abstract}
This paper, first, deals with the analytical controller design of wind turbines with variable rotor-resistance control. Wind turbines with variable rotor-resistance control, known as Limited Variable Speed Wind Turbine (LVS-WT), provide a limited variation of the generator speed. In the LVS-WT, the rotor current and, consequently, the out put power can be controlled by varying the rotor resistance. Then, modal and small signal analyses of the wind turbine are examined. It is found that for certain values of shaft stiffness, frequency of the mechanical modes coincides with the triple oscillation frequency appeared due to tower shadow effects. This in turn results in resonance phenomena magnifying the fluctuation of the generator power and electromagnetic torque. Next, the paper evaluates the impact of aerodynamic torque fluctuations on the dynamic response of the LVS-WT. In this way, analytical expressions for the fluctuations of the stator voltage and current, electromagnetic torque, and generator active power are proposed. These fluctuations arise because of the aerodynamic torque and rotor speed perturbations. The paper also investigates the effects of shaft stiffness, slope of power-slip curve, and rotor resistance on the wind turbine response. At the end, time domain simulations verify the results of theoretical analyses.
\end{abstract}

(C) 2018 Sharif University of Technology. All rights reserved.

\section{Introduction}

Wind turbine generators are mainly divided into four categories: Fixed Speed WTs (FSWTs), Limited Variable Speed WTs (LVS-WTs), DFIG-based WTs, and full converter-based WTs. In a grid-connected FSWT, the rotor speed is relatively fixed, and thus wind power variations will result in power fluctuations that adversely affect the output power quality of the generator [1]. Hence, the fixed speed wind turbines

*. Tel.: +983155912496; Fax: +983155912424

E-mail address: mrahimi@kashanu.ac.ir

doi: $10.24200 /$ sci. 2017.4363 have some disadvantages such as higher mechanical stress and poor-quality power control.

The DFIG and full converter-based wind turbines, known as variable speed WTs, provide controllability of the rotor speed with optimized extracted power, independent control of active and reactive power, and improved power quality indices [2]. The variable speed wind turbines have the following advantages compared to the fixed speed wind turbines: improved output power quality, increased energy output, and lower mechanical stress.

The LVS-WT, as shown in Figure 1, is equipped with a wound rotor induction generator that is directly connected to the grid. Some capacitor banks provide reactive power compensation, and a soft starter 


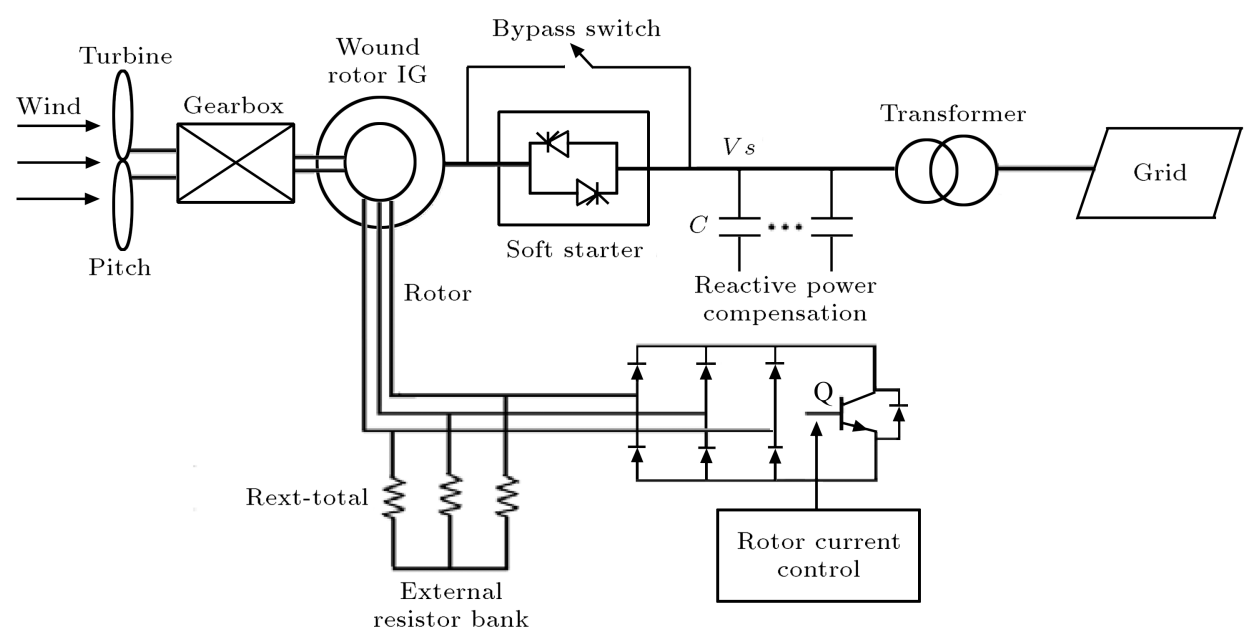

Figure 1. Limited variable speed wind turbine.

provides smooth grid connection. In addition, a set of three-phase external resistors, a three-phase diode bridge, and an IGBT switch are connected to the rotor windings.

This topology provides a limited variation of generator speed between 0 to $10 \%$ above synchronous speed [3]. Therefore, a wind turbine with the induction generator and variable rotor resistance is called the Limited Variable Speed Wind Turbine (LVS-WT). According to Figure 1, the effective value of the rotor resistance can vary by controlling the IGBT switch, $Q$. Then, the rotor current and, consequently, the rotor speed can be controlled by varying the rotor resistance. Consequently, in the LVS-WT, the output power of the generator system can be controlled, and the output power fluctuations can be reduced. In LVS-WT, by using optical coupling, slip rings and brushes requiring maintenance are not necessary [4]. A LVS-WT always operates at a variable slip above the synchronous speed and is not as flexible as a DFIG, but results in significantly less cost.

Until now, wind turbines producing up to 100 MW with variable rotor resistance have been installed in Iran at Manjil and Binalood sites. Further, several thousand megawatts of this technology have been installed all over the world since decades; thus, the control strategy of these wind turbines may play an important role in the dynamic performance of the grid. However, analytical studies with regard to this wind turbine are limited in the published literature.

Therefore, this paper deals with the controller design methodology of LVS-WT and then evaluates its dynamic performance with regard to tower shadow effects. Most of the research studies regarding the wind turbine generators have dealt with different behavior and control characteristics of the FSWT, DFIG, and full converter-based wind turbines.

The studies of the dynamic performance of the wind turbines are mainly dedicated to DFIG-based WTs and can be divided into several categories such as impact of WT on power system dynamics [5,6], grid fault response of WT [7,8], fault ride-through capability of WT [9,10], participation of WT in grid frequency stability [11,12], investigation of the WT drive train dynamics [13,14], and WT dynamic response under wind speed and aerodynamic power fluctuation $[15,16]$.

Unlike the other types of wind turbines, few studies have been published regarding controller design, analytical studies, and dynamic performance characteristics of LVS-WT. Control and performance evaluation of the LVS-WT has been studied by a few authors [17,18]. In [17], different methods of controlling the rotor resistance are proposed to achieve a constant output power beyond the rated wind speed. In [18], the voltage and frequency control of a three-phase self-excited slip-ring induction generator by variation of external rotor resistance is investigated. However, it deals with the stand-alone variable rotor-resistance induction generator, though not for a grid-connected one.

First, this paper develops a theoretical analysis of the elaborate controller design methodology of LVSWT. Then, modal analysis of the wind turbine generator is presented. It is shown that for certain values of shaft stiffness, frequency of the mechanical modes coincides with the triple oscillation frequency appeared due to tower shadow effects. This in turn results in resonance phenomena magnifying the fluctuation of the generator power and electromagnetic torque. Next, the impact of aerodynamic torque fluctuations, appeared due to wind shear and tower shadow effects, on the dynamic response of the LVS-WT is evaluated analytically. Further, analytical expressions for the fluctuations of the stator voltage and current, electromagnetic torque, and generator active power are proposed. These fluctuations arise because of the 
aerodynamic torque and rotor speed perturbations. At the end, effects of shaft stiffness, slope of power-slip curve, and rotor resistance on the WT response are examined. The studies are carried out on a wind farm consisting of several LVS-WTs connected to the grid.

\section{Wind turbine modeling and control}

The purpose of this section is to present the dynamic model and controller design of the LVS-WT. The generator model is developed based on the following assumptions:

(a) Positive direction for the stator and rotor currents is assumed into the generator;

(b) All system parameters and variables are in per unit and referred to the stator side in generator;

(c) The equations are given in dq-synchronous reference frame with the Stator Voltage Orientation (SVO).

The stator and rotor voltages and fluxes, electromagnetic torque, and stator output active power in reference frame rotating at angular speed of $\omega$ are given by [19]:

$$
\begin{aligned}
& v_{s d q}=R_{s} i_{s d q}+j \omega \psi_{s d q}+\frac{1}{\omega_{b}} \frac{d \psi_{s d q}}{d t} \\
& 0=R_{r} i_{r d q}+R_{e x t}^{\prime} i_{r d q}+j \omega_{2} \psi_{r d q}+\frac{1}{\omega_{b}} \frac{d \psi_{r d q}}{d t} \\
& \psi_{s d q}=L_{s} i_{s d q}+L_{m} i_{r d q} \\
& \psi_{r d q}=L_{m} i_{s d q}+L_{r} i_{r d q}, \\
& T_{e}=\frac{L_{m}}{L_{s}} \operatorname{Im}\left(\psi_{s d q} i_{r d q}{ }^{*}\right) \\
& P_{s}=-\operatorname{Re}\left(v_{s d q} i_{s d q}{ }^{*}\right)
\end{aligned}
$$

where $\psi, v$, and $i$ represent the flux, voltage, and current. Subscripts $s$ and $r$ denote the stator and rotor quantities, respectively. Also, $L_{s}$ and $L_{r}$ are the stator and rotor self-inductances, $L_{m}$ is the mutual inductance, $R_{e x t}^{\prime}$ is the rotor external resistance referred to the stator side, $\omega_{2}$ is the rotor slip frequency, $\omega_{b}$ is the base angular frequency, $\omega$ is the speed of $d-q$ reference frame, and $R_{s}$ and $R_{r}$ are the stator and rotor resistances. Superscript $*$ in Eq. (4) represents the conjugate operator.

The steady-state equations of the generator in the dq-synchronous reference frame with the stator voltage orientation, under the condition of neglecting the stator resistance, are given by:

$$
\begin{aligned}
& v_{s d}=V_{s} \cong-\omega_{s} \psi_{s q}, \\
& v_{s q}=0 \cong \omega_{s} \psi_{s d},
\end{aligned}
$$

where $V_{s}$ is the stator voltage amplitude, and $\omega_{s}$ equals 1 , and pu is the stator voltage frequency. From Eq. (6), we have:

$$
\begin{aligned}
& L_{s} i_{s d}+L_{m} i_{r d}=0, \\
& L_{m} i_{s q}+L_{r} i_{r q}=-1 .
\end{aligned}
$$

Replacing Eq. (7) into Eqs. (4) and (5) results in:

$$
\begin{aligned}
& T_{e}=\frac{L_{m}}{L_{s}} \psi_{s q} i_{r d}, \\
& P_{s}=-V_{s} i_{s d}=\frac{L_{m}}{L_{s}} V_{s} i_{r d} .
\end{aligned}
$$

Considering Eq. (9), $i_{s d}$ and $i_{r d}$ are the active power components of the stator and rotor currents, respectively. On the other hand, $i_{s q}$ and $i_{r q}$ are the reactive power components of the stator and rotor currents, respectively. Hence, $i_{r d}$ is responsible for the active power control. Figure 2 depicts the steady-state equivalent circuit of the induction machine with rotor variable resistance.

In LVS-WT, output active power regulation is realized by the $d$-axis rotor current control $i_{r d}$ through the rotor external resistance tuning.

In Figure 2, external resistance $R_{e x t}$ is responsible for the active power and electromagnetic torque control. Since the slip term appears only in the resistive component, $R_{\text {ext }}$ cannot directly affect the reactive power consumption of the generator. Also, most of the reactive power consumed by the induction machine is due to magnetizing reactance $X_{m}$, which is independent of $R_{\text {ext }}$.

By neglecting the resistance and leakage reactance of the stator, magnetizing voltage $E_{s}$ in Figure 2 is approximately equal to stator voltage $V_{s}$, i.e. $E_{s} \cong$ $V_{s}$, and consequently, the dq-components of the rotor current are given by:

$$
\begin{aligned}
& i_{r d} \cong-\frac{E_{s}}{\left(\frac{R_{r}+R_{e x t}}{s}\right)^{2}+X_{l r}^{2}}\left(\frac{R_{r}+R_{e x t}}{s}\right), \\
& i_{r q} \cong \frac{E_{s}}{\left(\frac{R_{r}+R_{e x t}}{s}\right)^{2}+X_{l r}{ }^{2}} X_{l r},
\end{aligned}
$$

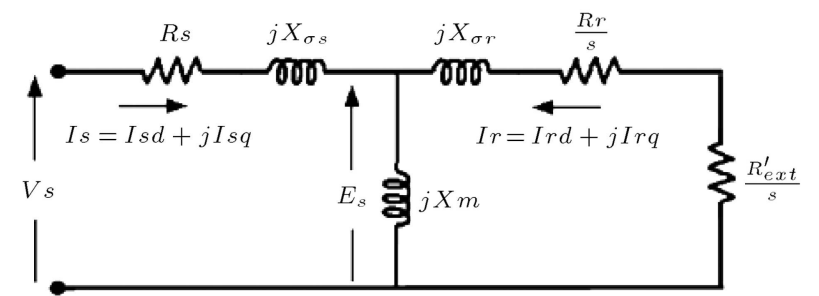

Figure 2. Equivalent circuit of the induction machine with rotor variable resistance. 
From Eqs. (10) and (11), we have:

$$
\frac{\left|i_{r d}\right|}{\left|I_{r}\right|} \cong \frac{\left(\frac{R_{r}+R_{e x t}}{s}\right)}{\sqrt{\left(\frac{R_{r}+R_{e x t}}{s}\right)^{2}+X_{l r}^{2}}}
$$

where $I_{r}$ is the rotor current amplitude. For sufficiently low slip operation, the rotor branch in Figure 2 is an equivalent resistance of high value in series with a much lower value of rotor leakage reactance; thus, the rotor circuit branch is almost resistive. Hence, according to Relation (12), $i_{r d}$ is the dominant component of the rotor current, and consequently, $\left|i_{r d}\right| \cong I_{r}$.

Therefore, for obtaining $i_{r d}$ during normal operation, we do not use PLL and Park transformations. In other words, by measuring the rotor current amplitude, it is possible to obtain $i_{r d}$ through the following approximation: $\left|i_{r d}\right| \cong I_{r}$.

\subsection{Rotor current control loop}

From Eqs. (2) and (3), the rotor dynamics is described in terms of rotor current and stator flux as follows:

$$
0=R_{r}^{\prime} i_{r d q}+R_{e x t}^{\prime} i_{r d q}+\frac{L_{r}^{\prime}}{\omega_{b}} \cdot \frac{d i_{r d q}}{d t}+j \omega_{2} L_{r}^{\prime} i_{r d q}+e_{d q}
$$

where the terms $R_{r}^{\prime}$ and $L_{r}^{\prime}$ in Eq. (13) are transient resistance and inductance of the rotor current dynamics and are given by:

$$
\begin{aligned}
R_{r}^{\prime} & =R_{r}+\left(\frac{L_{m}}{L_{s}}\right)^{2} R_{s}, \\
L^{\prime}{ }_{r} & =L_{r}-\frac{L_{m}^{2}}{L_{s}}
\end{aligned}
$$

In addition, the term $e_{d q}$ in Eq. (13) is the d-q rotor back-emf voltage induced in the rotor winding and reflects the effects of stator dynamics on rotor current dynamics. It is a function of stator flux and voltage and is given by:

$$
e_{d q}=\frac{L_{m}}{L_{s}}\left(v_{s d q}-j \omega_{r} \psi_{s d q}-\frac{R_{s}}{L_{s}} \psi_{s d q}\right),
$$

where $\omega_{r}$ in Eq. (15) is the rotor speed.

As stated before, $i_{r d}$ is the active component of the rotor current that can be used for active power control by the rotor external resistance regulation. From Eq. (13), the $d$-axis rotor current dynamics is given by:

$$
\begin{aligned}
& u_{d}=R_{r}^{\prime} i_{r d}+\frac{L_{r}^{\prime}}{\omega_{b}} \cdot \frac{d i_{r d}}{d t}-j \omega_{2} L_{r}^{\prime} i_{r q}+e_{d}, \\
& u_{d}=-R_{e x t}^{\prime} i_{r d}
\end{aligned}
$$

where $u_{d}=-R_{\text {ext }}^{\prime} i_{r d}$ is introduced as a control input used for the rotor current control.

For the sufficiently low operating slip, $i_{r q}$ is negligible; thus, $i_{r d}$ can be approximately replaced by $I_{r}$. Considering the rotor current controller to be PI, $K_{I_{r}}(s)=K_{P-I_{r}}+K_{I-I_{r}} / s$, so the following rotor current control loop, given in Figure 3, is obtained.

According to Figure 3, the open-loop bandwidth of the rotor current control is $\alpha_{s}=\frac{R_{r}^{\prime}}{L_{r}^{\prime}} \omega_{b}$, which is relatively small. By canceling the plant pole with the zero locations of the controller, in Figure 3, we have:

$$
\frac{K_{I-I_{r}}}{K_{P-I_{r}}}=\frac{R_{r}^{\prime}}{L_{r}^{\prime}} \omega_{b}
$$

Selecting $K_{P-I_{r}}=\frac{\alpha_{I} L_{r}^{\prime}}{\omega_{b}}$ and by taking Eq. (17) into account, the transfer function from $I_{r-r e f}$ to $I_{r}$ will be:

$$
G_{c l-I_{r}}=\frac{I_{r}(s)}{I_{r-r e f}(s)}=\frac{\alpha_{I}}{s+\alpha_{I}},
$$

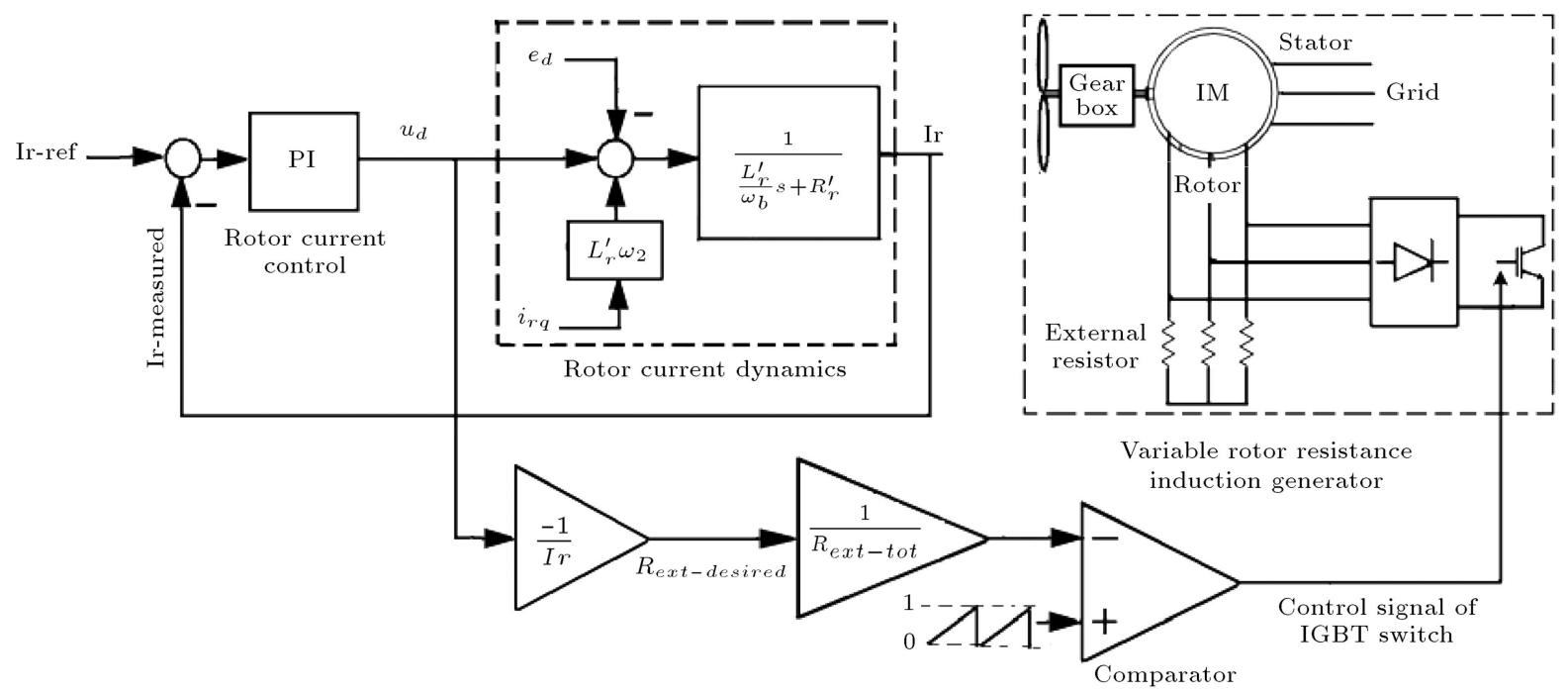

Figure 3. Rotor current control loop. 
where $\alpha_{I}$ is the closed-loop bandwidth of rotor current control $\alpha_{I}=\frac{K_{P-I_{r}}}{L_{r}^{\prime}} \omega_{b}$.

The stator current contains the fundamental grid frequency, while the rotor includes a low-frequency component. Therefore, the stator current is easily measured by an rms meter with a small time constant. On the other hand, measuring the rms value of the rotor current introduces a long time delay due to lower frequency waveform.

An efficient method for computing the rms value of the rotor current is based on three-phase to twophase transformations, defined as follows:

$$
\left[\begin{array}{c}
i_{r \alpha}(t) \\
i_{r \beta}(t)
\end{array}\right]=\frac{2}{3}\left[\begin{array}{ccc}
1 & -\frac{1}{2} & -\frac{1}{2} \\
0 & \frac{\sqrt{3}}{2}^{2} & -\frac{\sqrt{3}}{2}^{2}
\end{array}\right]\left[\begin{array}{c}
i_{r a}(t) \\
i_{r b}(t) \\
i_{r c}(t)
\end{array}\right],
$$

where subscripts $a, b, c, \alpha$, and $\beta$ denote the instantaneous values of the respective axis-rotor current components. The rms value of rotor current $I_{r-r m s}$ is then given by:

$$
I_{r-r m s}=\sqrt{\frac{i_{r \alpha}(t)^{2}+i_{r \beta}(t)^{2}}{2}} .
$$

Hence, using Eq. (20) to compute the rotor current $\mathrm{rms}$ value allows for a faster controller.

\subsection{Active power control loop}

In the LVS-WT, the stator active power injected to the grid can be controlled by the rotor current control through the rotor resistance regulation. Active power controller, as shown in Figure 4 determines the rotor reference current. Figure 4 depicts the output active power control loop, where $P_{s}$ and $P_{s-r e f}$ are the active power and reference active power of the stator.

Assuming the power controller to be PI, $K_{P}(s)=$ $k_{P-P}+\frac{k_{I-P}}{s}$, and by canceling pole $-\alpha_{I}$ with the zero of the controller, we have:

$$
\left\{\begin{array}{l}
\alpha_{P}=\frac{L_{m}}{L_{s}} \cdot k_{P-P} \cdot \alpha_{I} \cdot V_{s} \\
k_{I-P}=k_{P-P} \cdot \alpha_{I}
\end{array}\right.
$$

where $\alpha_{P}$ is the bandwidth of the stator active power control loop, and $\alpha_{I}$ is the closed-loop bandwidth of the rotor current. Then, the transfer function from $P_{s-r e f}$ to $P_{s}$ is given by:

$$
\frac{P_{s}}{P_{s-r e f}}=\frac{\alpha_{P}}{s+\alpha_{P}} \text {. }
$$

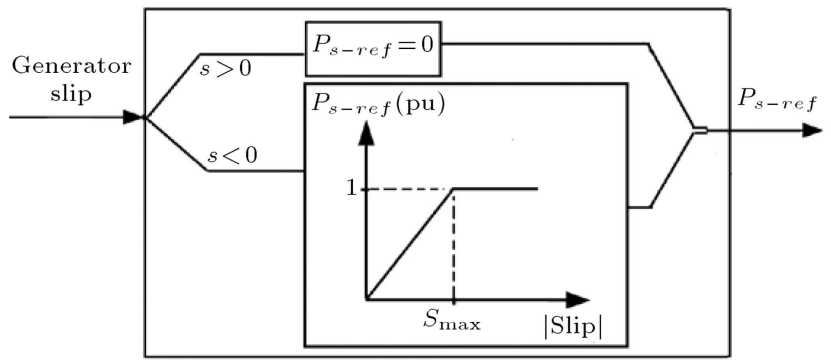

Figure 5. Power-slip curve (p-s characteristics).

Indeed, the rotor current control is the inner control loop, and the stator active power control represents the outer control loop.

The active power reference in Figure 4 is determined based on a slip-power curve. The slip-power curve generates the active power reference signal for the active power control loop. This reference signal is determined from a predefined characteristic of $P_{s-r e f}-$ slip, given in Figure 5 .

As shown in Figure 5, for the positive operating slip, the machine does not operate at the generator mode and the reference active power is set to zero. For the negative slip with the absolute value lower than $s_{\max }$, the reference active power is a linear function of slip. For the operating slips with $|s|>s_{\max }$, the active power reference is set to the rated power. At operating slips higher than $s_{\max }$, pitch control is activated, limiting the generator speed. In other words, the pitch control manages the generator speed at high wind speeds through rotor pitch angle to prevent the generator speed from becoming too high. At low wind speeds, the pitch angle is kept constant to an optimal value. According to Figure 5, the relation between the active power reference and generator slip is given by:

$$
\begin{aligned}
& P_{s-r e f}=g(s)= \\
& \begin{cases}0 & s \geq 0 \\
-\frac{s}{s_{\max }}=-K_{\text {power-curve }} \cdot s & -s_{\max } \leq s \leq 0 \\
1 & s \leq-s_{\max }\end{cases}
\end{aligned}
$$

where $K_{\text {power-curve }}$ in Eq. (23) as a design parameter is equal to $\frac{1}{s_{\max }}$ and corresponds to the slope of the slip-power curve.

\section{State space representation of limited variable speed WT}

In this section, the state space model of Single Machine-

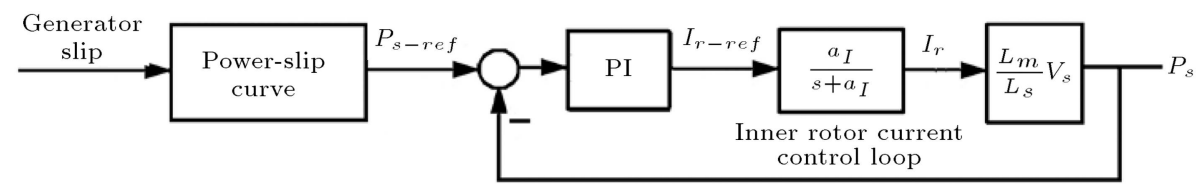

Figure 4. Stator active power control loop. 


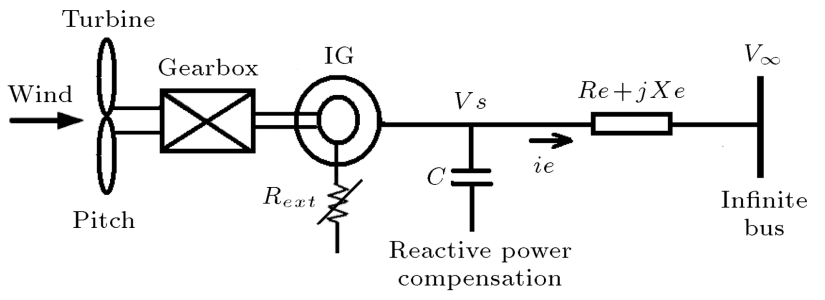

Figure 6. LVS-WT connected to the grid.

Infinite Bus (SMIB) system of Figure 6 is presented.

Considering Eqs. (1), (3), (13), and (15), the state equations of the stator and rotor dynamics as a function of stator flux and rotor current are given by:

$$
\begin{aligned}
\frac{1}{\omega_{b}} \frac{d \psi_{s d}}{d t}= & -\frac{R_{s}}{L_{s}} \psi_{s d}+\frac{R_{s} L_{m}}{L_{s}} i_{r d}+\omega_{s} \psi_{s q}+v_{s d} \\
\frac{1}{\omega_{b}} \frac{d \psi_{s q}}{d t}= & -\frac{R_{s}}{L_{s}} \psi_{s q}+\frac{R_{s} L_{m}}{L_{s}} i_{r q}-\omega_{s} \psi_{s d}+v_{s q} \\
\frac{L_{r}^{\prime}}{\omega_{b}} \frac{d i_{r d}}{d t}= & -R_{r}^{\prime} i_{r d}-R_{e x t}^{\prime} i_{r d}+\frac{R_{s} L_{m}}{L_{s}{ }^{2}} \psi_{s d} \\
& -\frac{L_{m}}{L_{s}} \omega_{r} \psi_{s q}+L_{r}^{\prime} \omega_{2} i_{r q}-\frac{L_{m}}{L_{s}} v_{s d} \\
\frac{L_{r}^{\prime}}{\omega_{b}} \frac{d i_{r q}}{d t}= & -R_{r}^{\prime} i_{r q}-R_{e x t}^{\prime} i_{r q}+\frac{R_{s} L_{m}}{L_{s}{ }^{2}} \psi_{s q} \\
& +\frac{L_{m}}{L_{s}} \omega_{r} \psi_{s d}-L_{r}^{\prime} \omega_{2} i_{r d}-\frac{L_{m}}{L_{s}} v_{s q} .
\end{aligned}
$$

In addition, state equations of the rotor current and stator power controllers are:

$$
\begin{aligned}
& \frac{d x_{5}}{d t}=k_{I-I_{r}} \cdot\left(i_{r d-r e f}-i_{r d}\right), \\
& \frac{d x_{6}}{d t}=k_{I-P_{s}} \cdot\left(P_{s-r e f}-P_{s}\right),
\end{aligned}
$$

where $P_{s}$ and $P_{s-r e f}$ are calculated according to Eqs. (5) and (23), respectively.

According to Figure 6, the state equations corresponding to grid current and capacitor voltage (terminal voltage) can be written as follows:

$$
\begin{aligned}
& \frac{L_{e}}{\omega_{b}} \frac{d i_{e d}}{d t}=v_{s d}-R_{e} i_{e d}+L_{e} \omega_{s} i_{e q}-v_{\infty d}, \\
& \frac{L_{e}}{\omega_{b}} \frac{d i_{e q}}{d t}=v_{s q}-R_{e} i_{e q}-L_{e} \omega_{s} i_{e d}-v_{\infty q}, \\
& \frac{C}{\omega_{b}} \frac{d v_{s d}}{d t}=-\frac{1}{L_{s}} \psi_{s d}+\frac{L_{m}}{L_{s}} i_{r d}-i_{e d}+C \omega_{s} v_{s q}, \\
& \frac{C}{\omega_{b}} \frac{d v_{s q}}{d t}=-\frac{1}{L_{s}} \psi_{s q}+\frac{L_{m}}{L_{s}} i_{r q}-i_{e q}-C \omega_{s} v_{s d} .
\end{aligned}
$$

Usually, a two-mass model is used for the modeling of the drive train in wind turbine generators. The twomass drive train model is given by [20]:

$$
\begin{aligned}
& \frac{d \omega_{r}}{d t}=\frac{T_{e}+k_{s h} \theta+D\left(\omega_{t}-\omega_{r}\right)}{2 H_{r}}, \\
& \frac{d \theta}{d t}=\omega_{b}\left(\omega_{t}-\omega_{r}\right) \\
& \frac{d \omega_{t}}{d t}=\frac{T_{e}-k_{s h} \theta-D\left(\omega_{t}-\omega_{r}\right)}{2 H_{t}}
\end{aligned}
$$

where $\omega_{r}$ and $\omega_{t}$ are the turbine and generator speeds in $(\mathrm{pu}), \theta$ is the shaft twist angle in ( $\mathrm{rad}), H_{r}$ and $H_{t}$ are the inertia constants of turbine and the generator in (sec), respectively, $k_{s h}$ is the shaft stiffness coefficient in (pu/elec. rad), $D$ is the damping coefficient in ( $\mathrm{pu}$ ), and $T_{e}$ and $T_{m}$ are the generator electrical torque and turbine aerodynamic torque, respectively, in (pu).

The aerodynamic torque, $T_{m}$, is extracted from the aerodynamic model of the wind turbine. The inputs of the aerodynamic model are the wind speed, $V_{w}$, the blade pitch angle, $\beta$, and the turbine speed, $\omega_{t}$. The output of the aerodynamic model is the turbine mechanical power, $P_{m}$. The following relationship is used to obtain $P_{m}$ from the wind power [21]:

$$
\begin{aligned}
& P_{m}=P_{\text {wind }} C_{P}(\lambda, \beta), \\
& P_{\text {wind }}=\frac{1}{2} \rho \pi R^{2} V_{w}^{3},
\end{aligned}
$$

where $P_{\text {wind }}$ is the power contained in the wind, $C_{P}$ is the is the power coefficient, $\rho$ is the air density, $R$ is the radius of the blades, and $V_{w}$ is the wind speed. Power coefficient, $C_{p}$, is a function of tip-speed ratio, $\lambda$, and blade pitch angle, $\beta$. Variable $\lambda$ is the ratio of the rotor blade tip speed and the wind speed. The aerodynamic torque is given by $T_{m}=P_{m} / \omega_{t}$.

The linearization of the aerodynamic torque under specific wind power, $P_{\text {wind } 0}$, and turbine operating speed, $\omega_{t 0}$, is given by:

$$
\Delta T_{m} \approx-\frac{P_{m 0}}{\omega_{t 0}{ }^{2}} \Delta \omega_{t}+P_{\text {wind } 0} \frac{d C_{P}(\lambda, \beta)}{d \lambda} \cdot \frac{d \lambda}{d \omega_{t}} \Delta \omega_{t} .
$$

\section{Modal and small signal stability analysis}

Eqs. (24)-(38) describe the dynamics of the LVS-WT of Figure 6 and may be written in the following form:

$$
\begin{aligned}
& x^{\bullet}=f(x, u), \\
& 0=g(x, u),
\end{aligned}
$$


where $x$ and $u$ are vectors of the state and input variables.

$x=\left[\psi_{s d}, \psi_{s q}, i_{r d}, i_{r q}, x_{5}, x_{6}, i_{e d}, i_{e q}, v_{s d}, v_{s q}, \omega_{r}, \theta, \omega_{t}\right]^{T}$,

$u=\left[V_{\infty}, V_{w}\right]^{T}$.

Linearizing Eq. (38) yields the linearized model of the wind turbine-generator in the following form:

$$
\Delta X^{\bullet}=A \cdot \Delta X+B \cdot \Delta u \text {. }
$$

Modal analysis is carried out on the system shown in Figure 6. Appendix A gives the parameters (in per unit) of a $660 \mathrm{~kW}, 690 \mathrm{~V}, 50 \mathrm{~Hz}$ LVS-WT used for the study. The controller parameters are shown in Appendix B. These parameters correspond to rotor current closed-loop bandwidth of 2 per unit $(100 \mathrm{~Hz})$ and power closed-loop bandwidth of $5 \mathrm{~Hz}$. Also, in the power-slip curve, given in Eq. (23), $K_{\text {power-curve }}$ is selected equal to 25 , i.e. $s_{\max }=0.04$.

The system modes and the corresponding participation factors are shown in Table 1. By using participation factors described in [22], the degree of contribution of each state variable in system modes is detected. Considering the results in Table 1, the following key points are found:

1. Modes $\lambda_{1,2}=-99.6 \pm j 3074$ and $\lambda_{3,4}=-115 \pm$ $j 2448$ are oscillatory ones corresponding to electrical state variables $i_{e d} . i_{e q}, v_{s d}$ and $v_{s q}$;

2. Mode $\lambda_{5}=-430$ is the $d$-axis rotor current mode, and $i_{r d}$ has the highest participation in this mode. This mode is very fast and its real part is highly dependent on the current closed-loop bandwidth. Therefore, the larger the rotor current closed-loop bandwidth, the larger the damping of the rotor current mode;

3. Modes $\lambda_{6,7}=-33.3 \pm j 292$ are oscillatory ones associated with the stator dynamics, with a corresponding natural frequency near the network frequency, i.e. 1 per unit. Stator variables, $\psi_{s d}$ and $\psi_{s q}$, have the most contribution in these modes;
4. Mode $\lambda_{8}=-83.9$ is a simple one associated with the rotor and stator electrical dynamics $(q-$ component stator flux and $q$-component rotor current);

5. Mode $\lambda_{9}=-47$ is rotor electrical one associated with state variable $x_{5}$ (see Eq. (28)). This mode is highly dependent on the rotor current open-loop bandwidth;

6. Modes $\lambda_{10,11}=-12 \pm j 22$ are electromechanical ones associated with generator speed, $\omega_{r}$, and power controller, $x_{6}$. The corresponding natural frequency is about $4 \mathrm{~Hz}$;

7. Modes $\lambda_{12,13}=-1.6 \pm j 3.9$ are the mechanical ones associated with the turbine and shaft dynamics (turbine speed and shaft twist angle). The corresponding natural frequency is $0.6 \mathrm{~Hz}$.

The frequency of this mode corresponds to the free-fixed eigen-frequency of the turbine. The free-fixed eigen-frequency of the turbine is approximately given by $\omega_{\text {free-fixed }}=\sqrt{\frac{k_{s h}}{2 H_{t}} \omega_{b}}$ and depends on the shaft stiffness and turbine inertia constant [21].

For the wind turbine of Appendix A, with $H_{t}=3$ sec and $k_{s h}=0.25$ pu/elec.rad, $\omega_{\text {free-fixed }}$ is obtained as $3.6 \mathrm{rad} / \mathrm{sec}$.

It is clear that by increasing $k_{s h}$, the frequency of these modes also increases. The frequency of the mechanical modes with $k_{s h}=1.5$ is approximately close to that of the triple oscillations appeared due to tower shadow effect. Hence, as will be shown in Section 6 , at $k_{s h}=1.5$, the resonance occurs and fluctuation of the generator power and electromagnetic torque is maximum.

\section{Dynamic response of LVS-WT under aerodynamic torque fluctuation}

The aerodynamic torque fluctuations in wind turbine generators are mainly created by the wind power

Table 1. The sample LVS-WT system modes and dominant state variables.

\begin{tabular}{ccccc}
\hline \multirow{2}{*}{ System modes } & & \multicolumn{2}{c}{$\begin{array}{c}\text { State variables with highest } \\
\text { participation factors }\end{array}$} \\
\cline { 1 - 2 } \cline { 5 - 6 }$\lambda_{1,2}$ & $-00.6 \pm j 3074$ & & $v_{s d}, v_{s q}$ & $i_{e d}, i_{e q}$ \\
$\lambda_{3,4}$ & $-115 \pm j 2448$ & & $i_{e d}$ & $i_{e q}$ \\
$\lambda_{5}$ & -430 & & $i_{r d}$ & - \\
$\lambda_{6,7}$ & $-33.3 \pm j 292$ & & $\psi_{s d}$ & $\psi_{s q}$ \\
$\lambda_{8}$ & -83.9 & & $\psi_{s q}$ & $i_{r q}$ \\
$\lambda_{9}$ & -47 & & $x_{5}$ & - \\
$\lambda_{10,11}$ & $-12 \pm j 22$ & & $\omega_{r}$ & $x_{6}$ \\
$\lambda_{12,13}$ & $-1.6 \pm j 3.9$ & & $\omega_{t}$ & $\theta$ \\
\hline
\end{tabular}


fluctuations due to wind speed variations, wind shear, and tower shadow effects [16].

In this section, the impact of aerodynamic torque fluctuations due to wind shear and tower shadow effects on the dynamic behavior of LVS-WT is evaluated.

The aerodynamic torque under specific wind speed can be expressed as follows [1]:

$$
T_{m}(t)=\left.T_{m}\right|_{0}+\Delta T_{m}(t)
$$

where $\left.T_{m}\right|_{0}$ is the average torque at the operating point and $\Delta T_{m}(t)$ is the torque fluctuations caused by the tower shadow and wind shear effects. The aerodynamic torque fluctuation is considered to have a value proportional to $\left.T_{m}\right|_{0}$. For wind turbines with 3 blades, the wind shear and tower shadow effects cause triple aerodynamic torque oscillations with frequency of $\omega_{p}$. For sinusoidal aerodynamic torque oscillation, $\Delta T_{m}(t)$ can be given by:

$$
\Delta T_{m}(t)=D_{T_{m}} \cos \left(\omega_{p} t\right),
$$

where $\omega_{p}$ is given by $\omega_{p}=\frac{3\left(\omega_{s}-\omega_{2}\right)}{n_{p} \cdot n_{\text {gear }}} \omega_{b}, n_{p}$ is the number of generator pole pairs, $n_{\text {gear }}$ is the gear box ratio, $\omega_{2}$ is the slip frequency in per unit, $\omega_{s}(1 \mathrm{pu})$ is the stator frequency, and $\omega_{b}\left(2 \pi f_{s}\right)$ is the base of angular frequency. The amplitude of mechanical power fluctuation is $10-20 \%$ of its average value [1]. Hence, for the linearized model of Section 4, by considering $\Delta T_{m}(t)$ as the sinusoidal input given in Eq. (42) and after applying the Fourier transform to Eq. (40), the variations of state variables are given by:

$$
\begin{aligned}
& \Delta x\left(\omega_{p}\right)=H\left(\omega_{p}\right) \cdot B \cdot D_{T_{m}}, \\
& H\left(\omega_{p}\right)=\left(j \omega_{p} \cdot I-A\right)^{-1},
\end{aligned}
$$

where complex $13 \times 1$ vector $\Delta x\left(\omega_{p}\right)$ represents sinusoidal values of state variables, $H\left(\omega_{p}\right)$ is a constant complex $13 \times 13$ matrix, and $B$ is a $13 \times 1$ vector with one nonzero component corresponding to the aerodynamic torque sinusoidal fluctuation.

Using Eq. (43), the steady-state fluctuation in the generator speed is given by:

$$
\Delta \omega_{r}(t)=K_{\cos -\omega_{r}} \cos \left(\omega_{p} t+\phi_{\omega_{r}}\right),
$$

where $K_{\cos -\omega_{r}}$ and $\phi_{\omega_{r}}$ are the amplitude and phase of the speed fluctuation. The fluctuation of generator speed also results in the fluctuations of the stator voltage magnitude and electromechanical torque.

The steady-state fluctuations of dq components of the stator voltage can be expressed as follows:

$$
\begin{aligned}
& \Delta v_{s d}=K_{\Delta v_{s d}} \cos \left(\omega_{p} t+\phi_{\Delta v_{s d}}\right), \\
& \Delta v_{s q}=K_{\Delta v_{s q}} \cos \left(\omega_{p} t+\phi_{\Delta v_{s q}}\right) .
\end{aligned}
$$

From Eq. (45), dq components of the stator voltage are given by:

$$
\begin{aligned}
v_{s d}(t)= & \left.v_{s d}\right|_{0}+\Delta v_{s d}(t)=\left.v_{s d}\right|_{0} \\
& +K_{\Delta v_{s d}} \cos \left(\omega_{p} t+\phi_{\Delta v_{s d}}\right), \\
v_{s q}(t)= & \left.v_{s q}\right|_{0}+\Delta v_{s q}(t)=\left.v_{s q}\right|_{0} \\
& +K_{\Delta v_{s q}} \cos \left(\omega_{p} t+\phi_{\Delta v_{s q}}\right) .
\end{aligned}
$$

After some manipulation, Eq. (46) is given by:

$$
\begin{aligned}
v_{s d q}(t)= & \left.v_{s d q}\right|_{0}+\Delta v_{s,+} e^{j\left(\omega_{p} t+\phi_{s,+}\right)} \\
& +\Delta v_{s,-} e^{-j\left(\omega_{p} t+\phi_{s,-}\right)}
\end{aligned}
$$

where $\left.v_{s d q}\right|_{0}$ corresponds to the average value of the stator voltage at the operating point, and $\Delta v_{s,+}, \phi_{s,+}$, $\Delta v_{s,-}$, and $\phi_{s,-}$ are given by:

$$
\begin{aligned}
\Delta v_{s,+} . e^{j \phi_{s,+}} & =\frac{K_{\Delta v_{s d}} e^{j \phi \Delta v_{s d}}+j K_{\Delta v_{s q}} e^{j \phi_{\Delta v_{s q}}}}{2}, \\
\Delta v_{s,-} . e^{j \phi_{s,-}} & =\frac{K_{\Delta v_{s d}} e^{-j \phi_{\Delta v_{s d}}}+j K_{\Delta v_{s q}} e^{-j \phi_{\Delta v_{s q}}}}{2} .
\end{aligned}
$$

From Eq. (47), the space vector of the stator voltage in the stationary reference frame, $v_{s \alpha \beta}$, can be represented by:

$$
\begin{aligned}
v_{s \alpha \beta}(t)= & \left.v_{s d q}\right|_{0} e^{j\left(\omega_{s} t+\theta_{0}\right)}+\Delta v_{s,+} e^{j\left(\left(\omega_{s}+\omega_{p}\right) t+\theta_{0}+\phi_{s,+}\right)} \\
& +\Delta v_{s,-} e^{j\left(\left(\omega_{s}-\omega_{p}\right) t+\theta_{0}-\phi_{s,-}\right)}
\end{aligned}
$$

where $\omega_{s}$ and $\theta_{0}$ are the phase and frequency of the stator voltage.

According to Eq. (49), the stator voltage is similar to an amplitude modulated waveform at $\omega_{p}$. This leads to two side-band frequency components with frequencies of $\omega_{s}-\omega_{p}$ and $\omega_{s}+\omega_{p}$.

Similar to the stator voltage, other electrical variables, such as stator flux and stator current, can also be expressed in the stationary reference frames as follows:

$$
\begin{aligned}
\psi_{s \alpha \beta}(t)= & \left.\psi_{s d q}\right|_{0} e^{j\left(\omega_{s} t+\theta_{0}\right)} \\
& +\Delta \psi_{s,+} e^{j\left(\left(\omega_{s}+\omega_{p}\right) t+\theta_{0}+\phi_{s,+}\right)} \\
& +\Delta \psi_{s,-} e^{j\left(\left(\omega_{s}-\omega_{p}\right) t+\theta_{0}-\phi_{s,-}\right)}, \\
i_{s \alpha \beta}(t)= & \left.i_{s d q}\right|_{0} e^{j\left(\omega_{s} t+\theta_{0}\right)} \\
& +\Delta i_{s,+} e^{j\left(\left(\omega_{s}+\omega_{p}\right) t+\theta_{0}+\phi_{s,+}\right)} \\
& +\Delta i_{s,-} e^{j\left(\left(\omega_{s}-\omega_{p}\right) t+\theta_{0}-\phi_{s,-}\right)},
\end{aligned}
$$


where $\left.\psi_{s d q}\right|_{0}$ and $\left.i_{s d q}\right|_{0}$ correspond to the average values; also, $\Delta \psi_{s,+}$ and $\Delta i_{s,+}$ are the upper side-band components, and $\Delta \psi_{s,-}$ and $\Delta i_{s,-}$ are the lower sideband components of the stator flux and rotor current, respectively.

Hence, in the stationary reference frame, the machine voltage, current, and flux can be decomposed into the mean component and lower and upper sideband components. The stator output active power can be calculated as follows:

$$
P_{s}=-\operatorname{Re}\left\{v_{s \alpha \beta} i_{s \alpha \beta}{ }^{*}\right\} .
$$

Replacing Eqs. (49) and (51) into Eq. (52) yields Eq. (53) as shown in Box I.

The electromagnetic power imported from the stator to the air-gap is given by:

$$
P_{s a g}=\operatorname{Re}\left\{j \omega_{s} \psi_{s d q} i_{s d q}{ }^{*}\right\}
$$

From Eq. (55), the electromagnetic torque, $T_{e}$, is given by:

$$
T_{e}=\frac{P_{s a g}}{\omega_{s y n}}=-\operatorname{Im}\left\{\omega_{s} \psi_{s d q} i_{s d q}{ }^{*}\right\},
$$

where $\omega_{\text {syn }}$ represents the synchronous speed and is equal to $1 \mathrm{pu}$.

Replacing Eqs. (50) and (51) into Eq. (56) yields Eq. (57) as shown in Box II.

According to Eqs. (53) and (57), under aerodynamic torque fluctuation, the stator active power and electromagnetic torque contain three components: 1) mean terms $P_{s 0}$ and $\left.T_{e 0}, 2\right)$ oscillating terms with frequency of $\left.\omega_{p}, 3\right)$ oscillating terms with frequency of $2 \omega_{p}$.

Considering Eqs. (54) (shown in Box I) and (58) (shown in Box II), the magnitude of oscillating terms with frequency of $2 \omega_{p}$ is obtained by the product of upper and lower side-band components. Hence, $2 \omega_{p}$ components of the electromagnetic torque and stator power have relatively negligible magnitudes, and $\omega_{p}$ components are the dominant oscillating terms.

\section{Simulation study}

In the following, the effects of shaft stiffness, rotor resistance, and slope of the slip-power curve, $K_{\text {power-curve }}$, on the dynamic behavior of the LVS-WT are investigated considering triple oscillations due to wind shear and tower shadow effects.

The system under study, shown in Figure 7, consists of ten $660 \mathrm{~kW}$ LVS-WT parameters connected to a $20 \mathrm{kV}$ distribution system. It exports power to a 130 $\mathrm{kV}$ grid through a $10 \mathrm{~km}, 20 \mathrm{kV}$ cable and transformers $\mathrm{T} 2$ and T3. Both transformers $\mathrm{T} 2$ and $\mathrm{T} 3$ are rated 15 MVA with the equivalent series impedance of $12.3 \%$. $\mathrm{T} 2$ and $\mathrm{T} 3$ are supplied from a $130 \mathrm{kV}$ grid with short circuit level of 1625 MVA. The LVS-WT parameters used in this simulation are given in Appendix A.

The simulation results correspond to wind speed of $11 \mathrm{~m} / \mathrm{sec}$. In addition, the amplitude of aerodynamic power fluctuation due to tower shadow and wind shear

$$
\begin{aligned}
P_{s}= & P_{s 0}+P_{s-\cos } \cos \left(\omega_{p} t\right)+P_{s-\sin } \sin \left(\omega_{p} t\right) \\
& +P_{s-\cos 2} \cos \left(2 \omega_{p} t\right)+P_{s-\sin 2} \sin \left(2 \omega_{p} t\right)
\end{aligned}
$$

where:

$$
\begin{gathered}
{\left[\begin{array}{l}
P_{s 0} \\
P_{s-\cos } \\
P_{s-\sin } \\
P_{s-\cos 2} \\
P_{s-\sin 2}
\end{array}\right]=\left[\begin{array}{cccccc}
v_{s d 0} & v_{s q 0} & \Delta v_{s d,+} & \Delta v_{s q,+} & \Delta v_{s d,-} & \Delta v_{s q,-} \\
\Delta v_{s d,+}+\Delta v_{s d,-} & \Delta v_{s q,+}+\Delta v_{s q,-} & v_{s d 0} & v_{s q 0} & v_{s d 0} & v_{s q 0} \\
\Delta v_{s q,-}-\Delta v_{s q,+} & \Delta v_{s d,+}-\Delta v_{s d,-} & v_{s q 0} & -v_{s d 0} & -v_{s q 0} & v_{s d 0} \\
0 & 0 & \Delta v_{s d,-} & \Delta v_{s q,-} & \Delta v_{s d,+} & \Delta v_{s q,+} \\
0 & 0 & \Delta v_{s q,-} & -\Delta v_{s d,-} & -\Delta v_{s q,+} & \Delta v_{s d,+}
\end{array}\right]} \\
{\left[\begin{array}{l}
i_{s d 0} \\
i_{s q 0} \\
\Delta i_{s d,+} \\
\Delta i_{s q,+} \\
\Delta i_{s d,-} \\
\Delta i_{s q,-}
\end{array}\right] .}
\end{gathered}
$$




$$
\begin{aligned}
T_{e}= & T_{e 0}+T_{e-\cos } \cos \left(\omega_{p} t\right)+T_{e-\sin } \sin \left(\omega_{p} t\right) \\
& +T_{e-\cos 2} \cos \left(2 \omega_{p} t\right)+T_{e-\sin 2} \sin \left(2 \omega_{p} t\right) .
\end{aligned}
$$

where:

$$
\left[\begin{array}{l}
T_{e 0} \\
T_{e-\cos } \\
T_{e-\sin } \\
T_{e-\cos 2} \\
T_{e-\sin 2}
\end{array}\right]=
$$

$$
\begin{aligned}
& {\left[\begin{array}{cccccc}
-\psi_{s q 0} & \psi_{s d 0} & -\Delta \psi_{s q,+} & \Delta \psi_{s d,+} & -\Delta \psi_{s q,-} & \Delta \psi_{s d,-} \\
-\Delta \psi_{s q,+}-\Delta \psi_{s q,-} & \Delta \psi_{s d,+}+\Delta \psi_{s d,-} & -\psi_{s q 0} & \psi_{s d 0} & -\psi_{s q 0} & \psi_{s d 0} \\
\Delta \psi_{s d,-}-\Delta \psi_{s d,+} & \Delta \psi_{s q,-}-\Delta \psi_{s q,+} & \psi_{s d 0} & \psi_{s q 0} & -\psi_{s d 0} & -\psi_{s q 0} \\
0 & 0 & -\Delta \psi_{s q,-} & \Delta \psi_{s d,-} & -\Delta \psi_{s q,+} & \Delta \psi_{s d,+} \\
0 & 0 & \Delta \psi_{s d,-} & \Delta \psi_{s q,-} & -\Delta \psi_{s d,+} & -\Delta \psi_{s q,+}
\end{array}\right]} \\
& {\left[\begin{array}{l}
i_{s d 0} \\
i_{s q 0} \\
\Delta i_{s d,+} \\
\Delta i_{s q,+} \\
\Delta i_{s d,-} \\
\Delta i_{s q,-}
\end{array}\right]}
\end{aligned}
$$

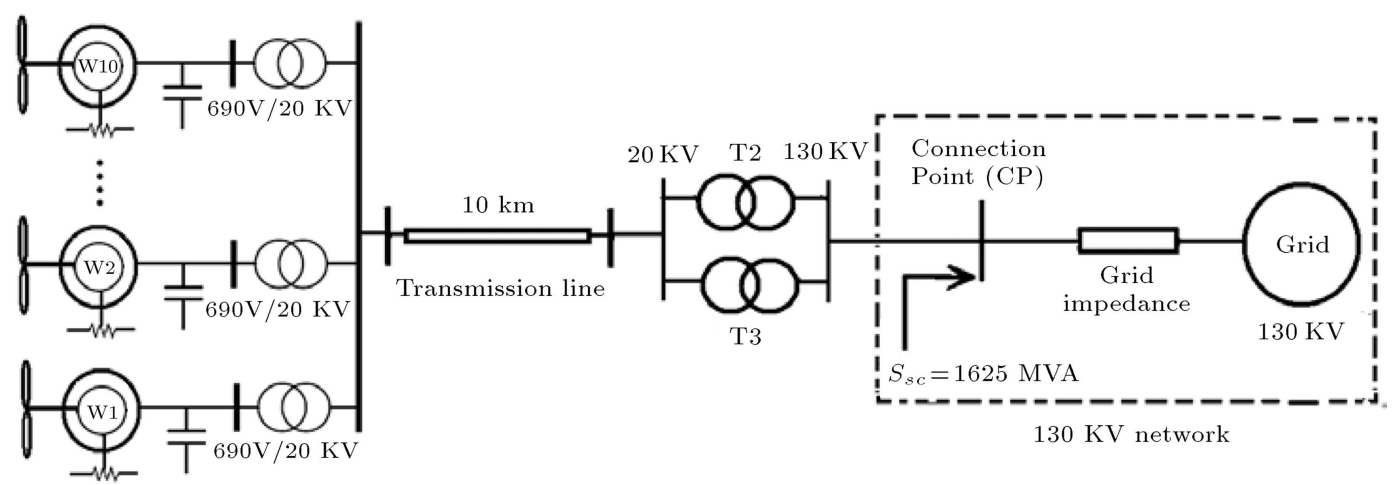

Figure 7. The system under study.

effects is considered to be $10 \%$ of its average value. For the simulated LVS-WT, with $n_{p}=2, n_{\text {gear }}=52.7$, $\omega_{b}=314 \mathrm{rad} / \mathrm{sec}$, and operating slip in the range of -0.04-0, triple oscillation frequency, $\omega_{p}$, varies in the range of 1.42-1.45 HZ (8.9-9.1 rad/sec).

\subsection{Effects of shaft stiffness}

Figure 8 shows the dynamic response of the LVS-WT with two different values of wind turbine shaft stiffness, i.e. $K_{s h}=0.25 \mathrm{pu} /$ elec.rad and $K_{s h}=1.5 \mathrm{pu} /$ elec.rad.

The simulation results correspond to wind speed of $11 \mathrm{~m} / \mathrm{sec}$, and slope of the slip-power curve, $K_{\text {power-curve, }}$ is considered equal to 25 , i.e. $s_{\max }=$ 0.04. In addition, amplitude of aerodynamic power fluctuation due to tower shadow and wind shear effects is considered to be 10 percent of its average value.

Considering Figure 8, the operating points of the wind farm system without tower shadow effects are as follows.

Turbine aerodynamic power, $P_{t 0} \cong 10 \times 539 \mathrm{KW}$, generator speed, $\omega_{r}=1546 \mathrm{rpm}$, and stator output active power, $P_{s} \cong 10 \times 508 \mathrm{~kW}$.

According to Figure 8, for the case with $k_{s h}=$ $0.25 \mathrm{pu} / \mathrm{elec} . \mathrm{rad}$, low-frequency fluctuations of the generator speed, stator active power, electromagnetic torque, and stator voltage are lower than those for the case with $k_{s h}=1.5 \mathrm{pu} /$ elec.rad. The frequency of the oscillations appeared in Figure 8 is $1.46 \mathrm{~Hz}$ 


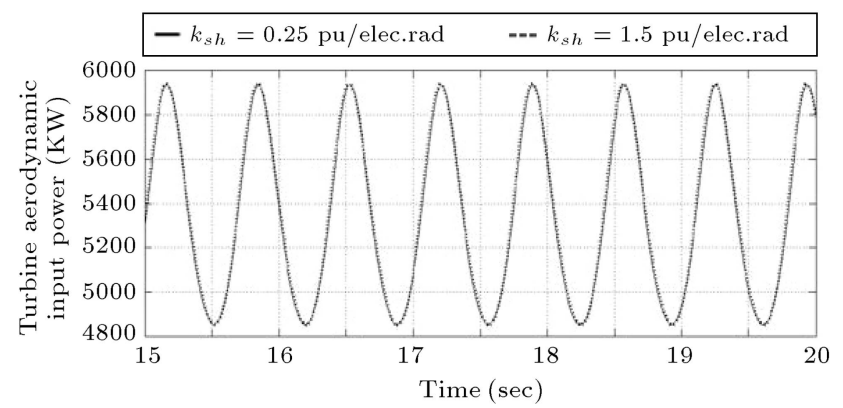

(a)

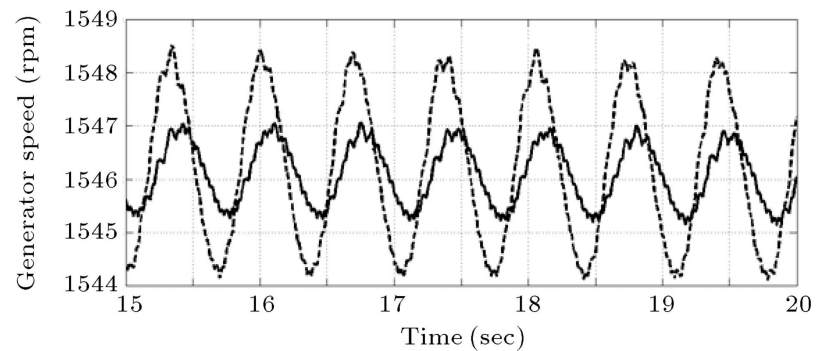

(b)

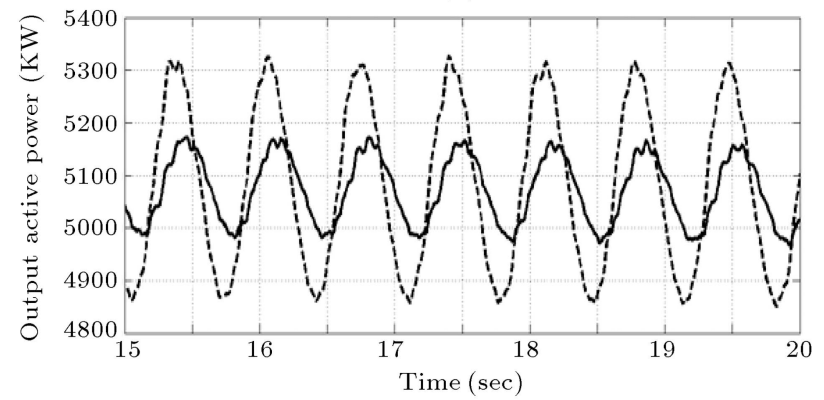

(c)

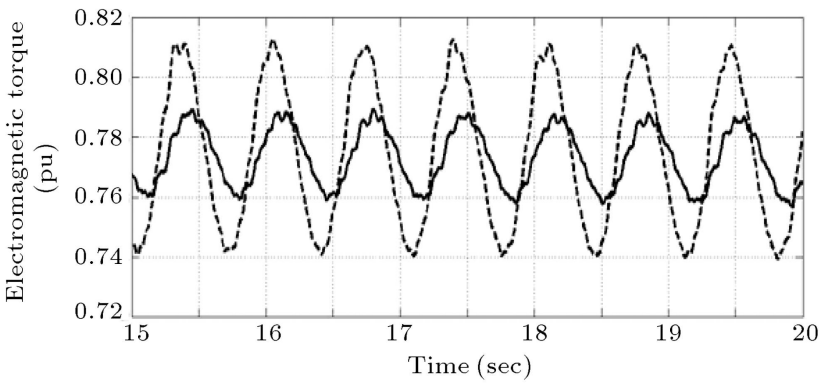

(d)

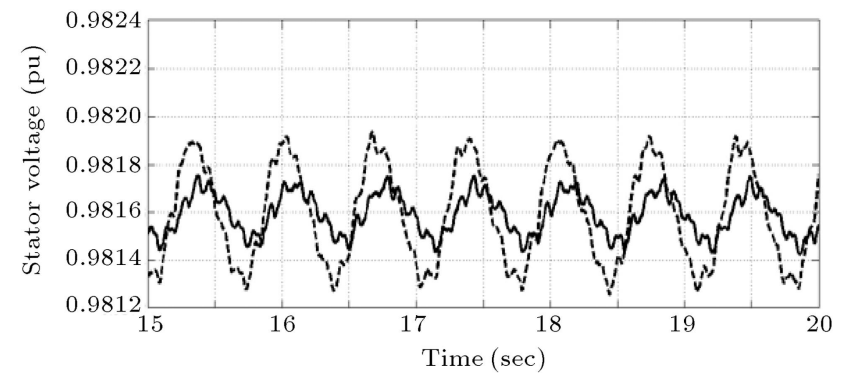

(e)

Figure 8. Dynamic response of LVS-WT with two different values of shaft stiffness: (a) Turbine aerodynamic input power, (b) generator speed, (c) stator active power, (d) electromagnetic torque, and (e) stator voltage magnitude. corresponding to triple oscillation frequency. Hence, for the case with $k_{s h}=1.5 \mathrm{pu} /$ elec.rad, fluctuations of the generator response are larger. This is because as stated in Section 4, for $k_{s h}=1.5 \mathrm{pu} /$ elec.rad, the natural oscillation frequency of mechanical modes $\lambda_{12,13}$ is close to the triple oscillation frequency, i.e. $1.46 \mathrm{~Hz}$.

\subsection{Effects of slope of slip-power curve}

Figure 9 shows the dynamic response of the LVSWT with two different values of $K_{\text {power-curve, }}$ i.e. $K_{\text {power-curve }}=25$ and $K_{\text {power-curve }}=50$.

The simulation results correspond to wind speed of $11 \mathrm{~m} / \mathrm{sec}$, and amplitude of aerodynamic power

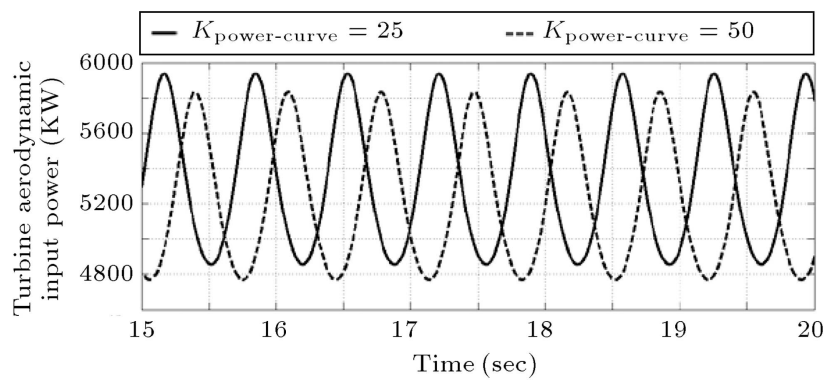

(a)

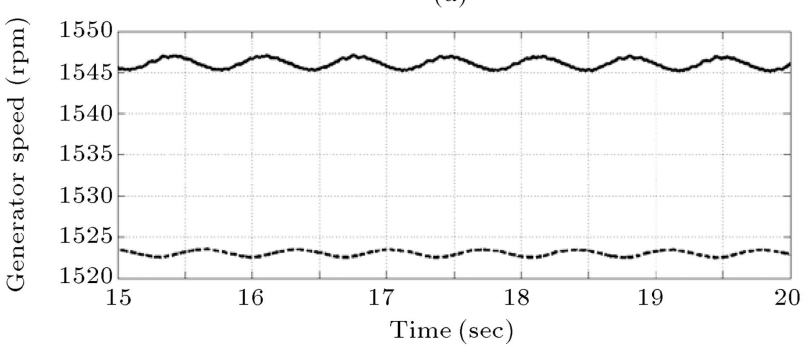

(b)

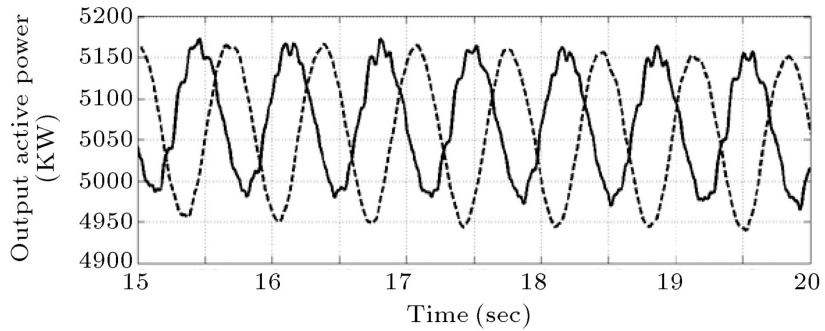

(c)

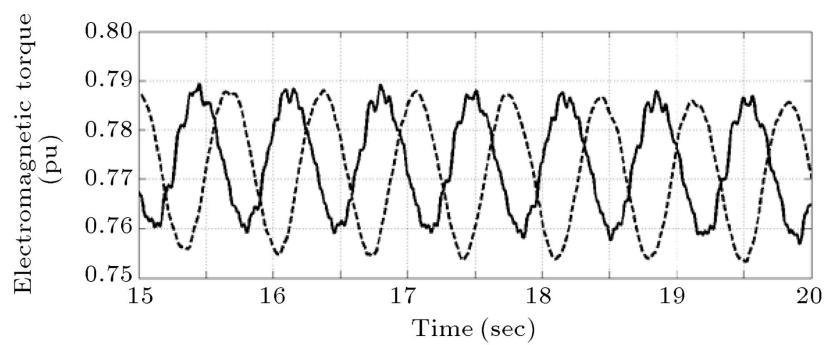

(d)

Figure 9. Dynamic response of LVS-WT with two different values of slope of slip-power curve: (a) Turbine aerodynamic input power, (b) generator speed, (c) stator active power, and (d) electromagnetic torque. 
fluctuation is considered to be 10 percent of its average value.

$K_{\text {power-curve is a design parameter of the power }}$ control, and it determines the maximum operating slip of the generator. The maximum operating slip for $K_{\text {power-curve }}=25$ is $4 \%$ and for $K_{\text {power-curve }}=50$ is $2 \%$. According to Figure 9, the average operating speed of the generator for $K_{\text {power-curve }}=25$ is $1546 \mathrm{rpm}$ and for $K_{\text {power-curve }}=50$ is $1523 \mathrm{rpm}$. This results in larger aerodynamic power for $K_{\text {power-curve }}=25$. According to Figure 9, low-frequency fluctuations of the stator output active power and electromagnetic torque for $K_{\text {power-curve }}=25$ are lower than those for $K_{\text {power-curve }}=50$. Hence, in the case with $K_{\text {power-curve }}=25$, mechanical stress and torque pulsations on the wind turbine shaft reduce and power quality of the generator improves.

\subsection{Effects of rotor resistance}

Figure 10 compares the dynamic responses of the LVSWT with those of the fixed speed WT (FSWT) under aerodynamic power fluctuation.

According to Figure 10, the average operating speed of the generator in LVS-WT is $1546 \mathrm{rpm}$ and in FSWT is $1508 \mathrm{rpm}$. This results in larger aerodynamic power in LVS-WT. According to Figure 10, low-frequency fluctuations of the stator active power, electromagnetic torque, and stator voltage for LVS-WT are lower than those for FSWT. Hence, in the case with LVS-WT, mechanical stress and torque pulsations on the wind turbine shaft reduce, and power quality of the generator improves.

In other words, in LVSWT, the mechanical stresses, torque and power pulsations decrease; as a result, power quality of the generator improves. In addition, in LVS-WT, the average output power and, consequently, the efficiency of the aerodynamic energy conversion are higher than those in FSWT.

\subsection{Control system modification}

In the following, the wind turbine control system is modified to reduce the power and torque fluctuations in the case with $k_{s h}=1.5$ pu/elec.rad. As stated before, for the case with $k_{s h}=1.5 \mathrm{pu} /$ elec.rad, the natural oscillation frequency of the mechanical modes, $\lambda_{12,13}$, is close to $3 p$ oscillation frequency, i.e. $1.46 \mathrm{~Hz}$; thus, fluctuations of the generator response are larger. Hence, to reduce the system response fluctuations, it is sufficient to change the value of natural oscillation frequency of the mechanical modes. According to Section 4 , the natural oscillation frequency of the mechanical modes, known as the free-fixed eigen-frequency, is approximately given by $\omega_{\text {free-fixed }}=\sqrt{\frac{k_{s h}}{2 H_{t}} \omega_{b}}$ and depends on shaft stiffness, $k_{s h}$, and turbine inertia constant. Hence, $\omega_{\text {free-fixed }}$ can change by actively varying the shaft stiffness. According to Eq. (34), if electrical

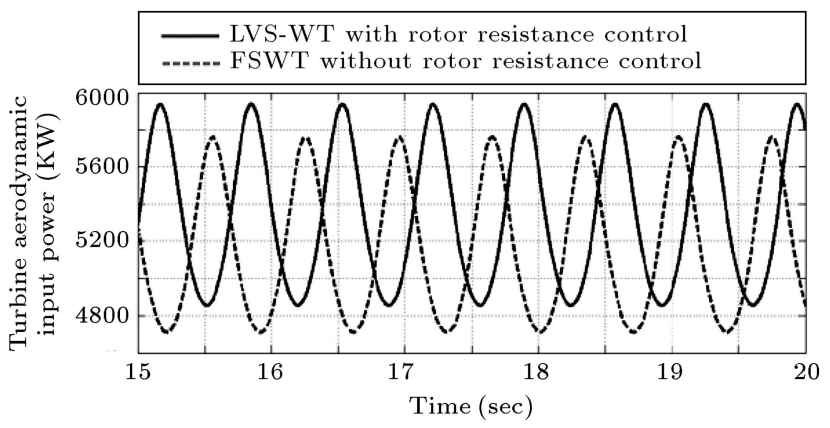

(a)

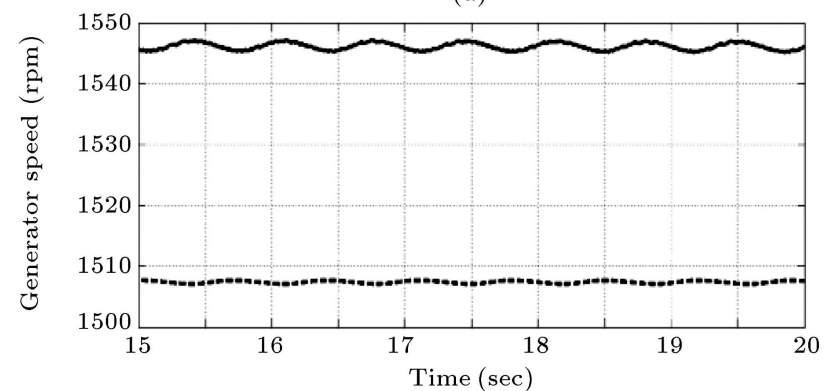

(b)

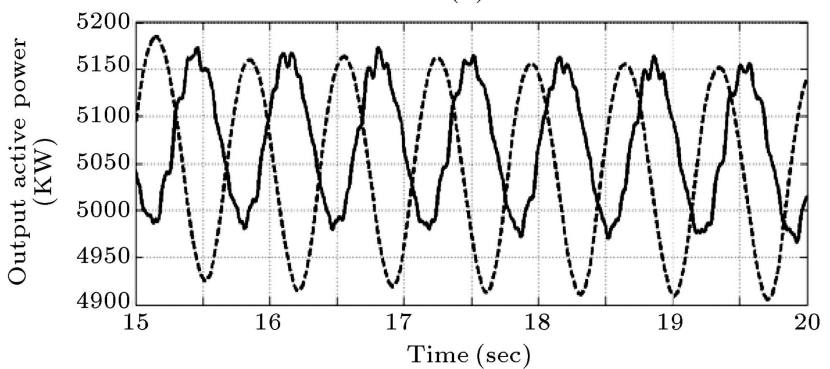

(c)

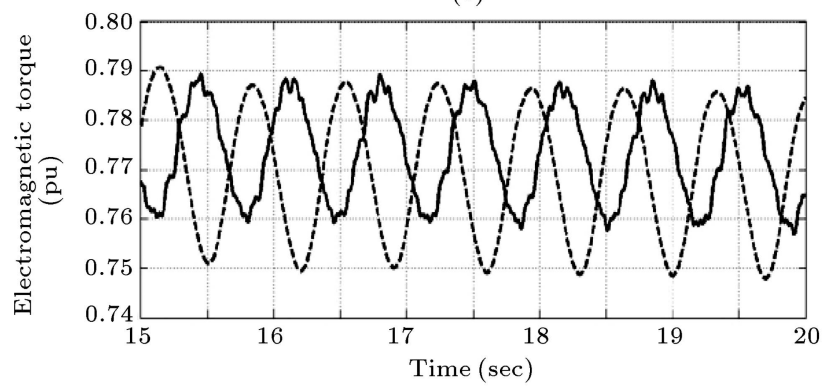

(d)

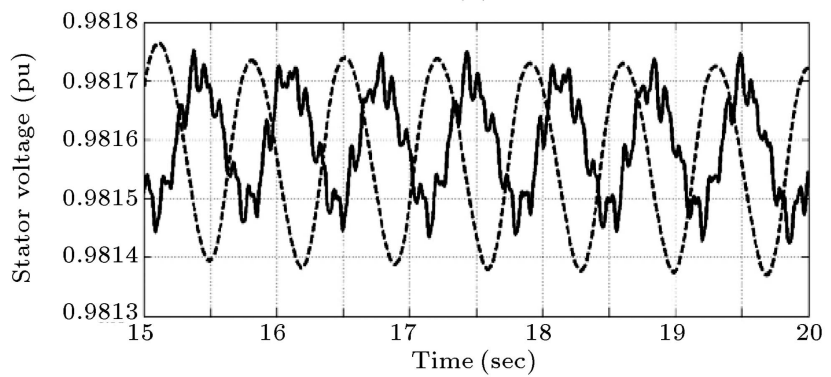

(e)

Figure 10. Dynamic response of WT with and without rotor external resistance control: (a) Turbine aerodynamic input power, (b) generator speed, (c) stator output power, (d) electromagnetic torque, and (e) stator voltage magnitude. 


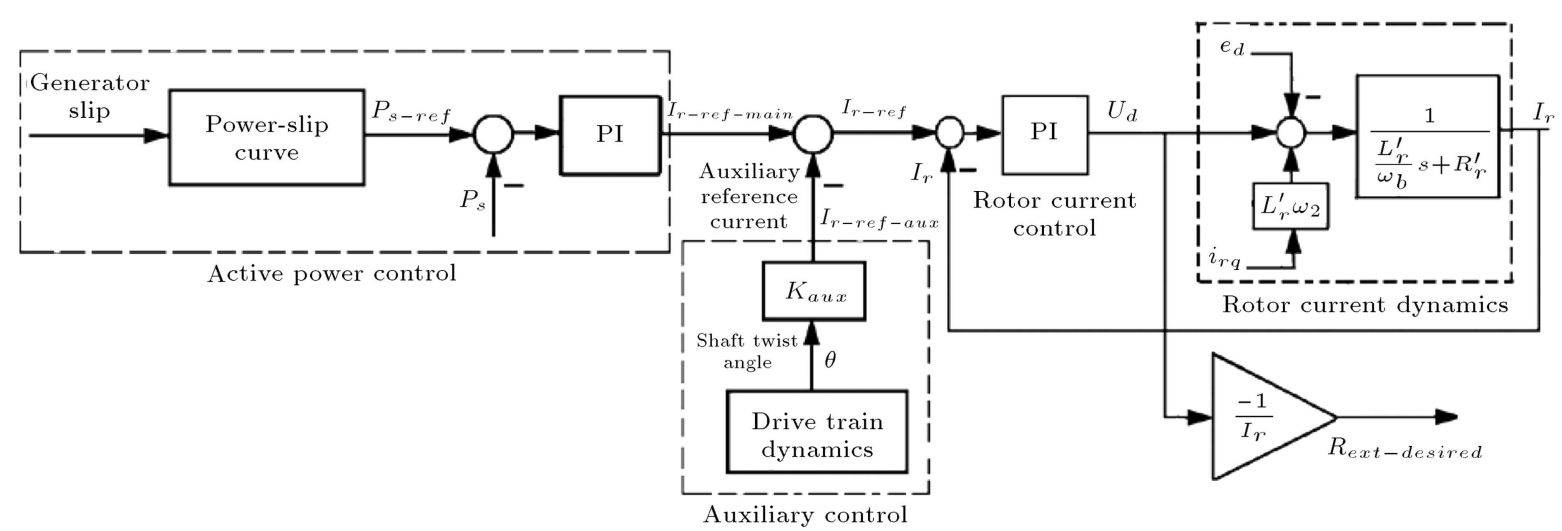

Figure 11. Modified wind turbine control system.

torque, $T_{e}$, contains additional auxiliary term that is proportional to shaft twist angle $\theta, k_{s h}$ can be changed actively. This additional auxiliary torque is provided through modifying the rotor reference current, as given in Figure 11.

Figure 11 shows the modified wind turbine control system for actively varying the shaft stiffness. In Figure 11, the rotor current comprises two terms: the first term, $I_{r-r e f-m a i n}$, is the main reference current that regulates the active power; the second term, $I_{r-\text { ref-aux }}$, is known as the auxiliary reference current. The auxiliary reference current, $I_{r-r e f-a u x}$, is proportional to shaft twist angle $\theta$, while $I_{r-r e f-a u x}$ and $\theta$ are out of phase. This, in turn, provides an auxiliary electrical torque that is proportional to $\theta$, and consequently increases the shaft stiffness factor actively. Figure 12 depicts the dynamic response of the LVS-WT for $K_{s h}=1.5 \mathrm{pu} /$ elec.rad, with and without control system modification. Parameter $K_{\text {aux }}$ in Figure 11 is selected equal to 0.5 , and thus, $K_{s h}$ is actively changed from 1.5 to 2 . According to Figure 12, in the case with modified control system, the control system provides higher external rotor resistance, and this in turn results in higher average value of generator speed at the operating point and higher rotor losses. Considering Figure 12(a), fluctuation of the generator speed with/without modified control system remains unchanged. However, according to Figure 12(b) and

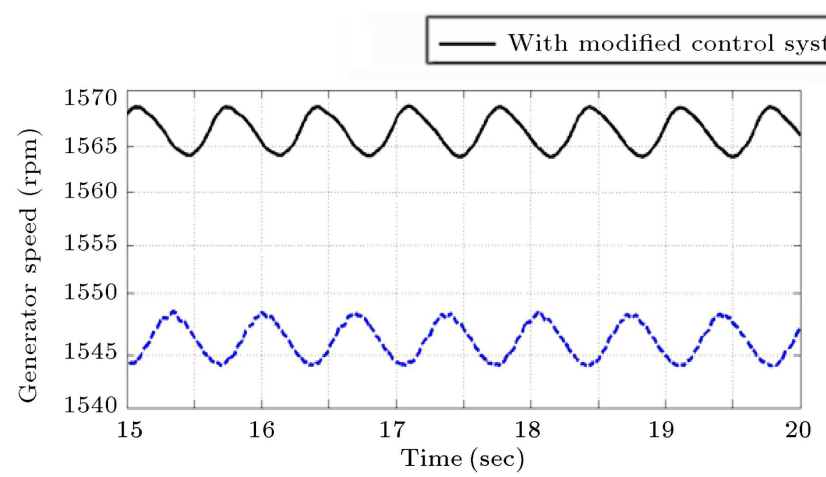

(a)

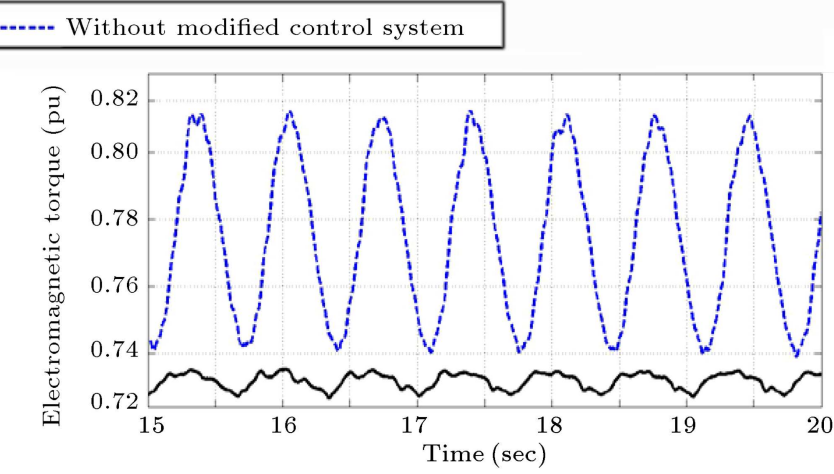

(b)

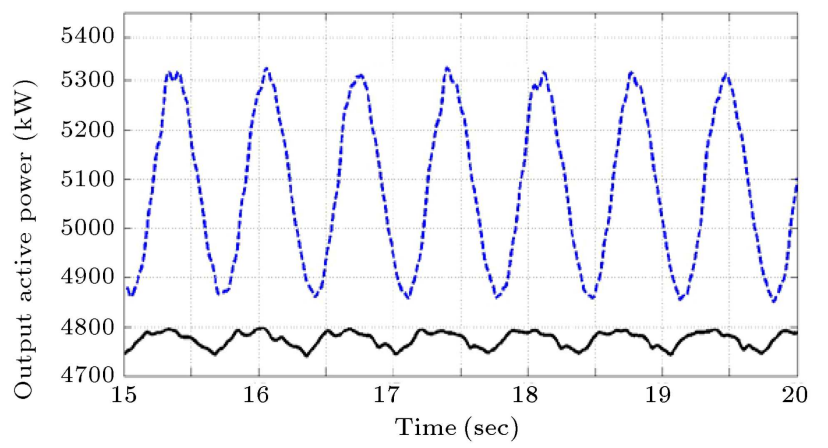

(c)

Figure 12. Dynamic response of the LVS-WT for $K_{s h}=1.5 \mathrm{pu} /$ elec.rad, with and without control system modification: (a) Generator speed, (b) electromagnetic torque, and (c) output active power. 
(c), for the case with modified control system, the amplitudes of the low-frequency fluctuations of electromagnetic torque and active power are lower than those for the case without control system modification.

\section{Conclusion}

This paper deals with the analytical controller design in LVS-WT, and then examines its dynamic performance with regard to aerodynamic torque fluctuations appeared due to tower shadow effects.

Modal analysis of the wind turbine depicts that, for certain values of shaft stiffness, frequency of the mechanical modes coincides with the triple oscillation frequency magnifying the fluctuation of the generator power and electromagnetic torque.

The paper develops analytical expressions for the fluctuations of the stator voltage and current, electromagnetic torque, and generator active power. These fluctuations arise because of the aerodynamic torque and rotor speed perturbations. It is found that in the stationary reference frame, the generator voltage, current, and flux can be decomposed into the mean component and lower and upper side-band components.

According to the obtained analytical results, under aerodynamic torque fluctuation, the stator active power and electromagnetic torque contain three components: mean terms, oscillating terms with frequency of $\omega_{p}$, and oscillating terms with frequency of $2 \omega_{p}$. It is shown that $2 \omega_{p}$ components of the electromagnetic torque and stator power have relatively negligible magnitudes, and $\omega_{p}$ components are the dominant oscillating terms. The paper also examines the effects of shaft stiffness, slope of power-slip curve, and rotor resistance on the WT response. The studies are carried out on a wind farm consisting of LVS-WTs connected to the grid.

\section{References}

1. Rahimi, M. and Parniani, M. "Dynamic behavior and transient stability analysis of fixed speed wind turbines", Renewable Energy, 34, pp. 2613-2624 (2009).

2. Rahimi, M. and Parniani, M. "Grid-fault ride-through analysis and control of wind turbines with doubly fed induction generators", Elec. Power Sys. Res., 80, pp. 184-195 (2010).

3. Vittal, V. and Ayyanar, R., Grid Integration and Dynamic Impact of Wind Energy, 1st Ed., Springer (2013).

4. Jatinkumar, P., Gupta, S.P., and Singh, S.P. "Comparison of control techniques for rotor current control of line-excited slip-ring IG for WECS", Proc. Int. Conf. Computational Intelligence and Communication Networks (CICN) (2010).
5. Tsourakis, G., Nomikos, B.M., and Vournas, C.D. "Effect of wind parks with doubly fed asynchronous generators on small signal stability", Elec. Power Sys. Res., 79, pp. 190-200 (2009).

6. Dominguez-Garcia, J.L., Gomis-Bellmunt, O., Bianchi, F.D., and Sumper, A. "Power oscillation damping supported by wind power: A review", Renewable and Sustainable Energy Reviews, 16, pp. 4994-5006 (2012).

7. Pannell, G., Atkinson, D.J., and Zahawi, B. "Analytical study of grid-fault response of wind turbine doubly fed induction generator", IEEE Trans. Energy Conversion, 25, pp. 1081-1091 (2010).

8. Rola, X., NA, CO., Rcoles, F., and Pedra, J. "Doubly fed induction generator subject to symmetrical voltage sags", IEEE Trans. Energy Conversion, 26, pp. 12191229 (2011).

9. Rahimi, M. and Parniani, M. "Coordinated control approaches for low-voltage ride-through enhancement in wind turbines with doubly fed induction generators", IEEE Trans. Energy Conversion, 25, pp. 873883 (2010).

10. Rahimi, M. and Parniani, M. "Low voltage ridethrough capability improvement of DFIG-based wind turbines under unbalanced voltage dips", Electrical Power and Energy Systems, 60, pp. 82-95 (2014).

11. Anaya-Lara, O., Hughes, F.M., Jenkins, N., and Strbac, G. "Contribution of DFIG- based wind farms to power system short-term frequency regulation", IEE Proc. Gen. Transm. Distri., 153, pp. 164-70 (2006).

12. Mauricio, J.M., Marano, A., Gomez-Exposito, A., and MartinezRamos, J.L. "Frequency regulation contribution through variable-speed wind energy conversion systems", IEEE Trans. Power Systems, 24, pp. 173180 (2009).

13. Muyeen, S., Ali, M., Takahashi, R., Murata, T., and Tamura, J. "Damping of blade-shaft torsional oscillations of wind turbine generator", Electric Power Components and Systems, 36, pp. 195-211 (2008).

14. Yang, L., Xu, Z., Ostergaard, J., Dong, Z., Wong, K., and Ma, X. "Oscillatory stability and eigenvalue sensitivity analysis of a DFIG wind turbine system", IEEE Trans. Energy Convers., 26, pp. 328-339 (2011).

15. Dolan, D.S.L. and Lehn, P.W. "Simulation model of wind turbine $3 p$ torque oscillations due to wind shear and tower shadow", IEEE Trans Energy Convers., 21, pp. 717-724 (2006).

16. $\mathrm{Hu}, \mathrm{W} ., \mathrm{Su}, \mathrm{C}$., and Chen, Z. "Impact of wind shear and tower shadow effects on power system with large scale wind power penetration", IEEE Conf. Industrial Electronics Society (IECON) (2011).

17. Burnham, D.J., Santoso, S., and Muljadi, E. "Variable rotor-resistance control of wind turbine generators", IEEE Conf. Power \& Energy Society General Meeting (2009). 
18. Chan, T.F., Nigim, K.A., and Lai, L.L. "Voltage and frequency control of self-excited slip-ring induction generators", IEEE Trans Energy Conversion, 19, pp. 81-87 (2004).

19. Rahimi, M. and Parniani, M. "Efficient control scheme of wind turbines with doubly-fed induction generators for low voltage ride-through capability enhancement", IET Journal Renewable Power Generation, 4, pp. 242$252(2010)$.

20. Rahimi, M. and Parniani, M. "Dynamic behavior analysis of doubly-fed induction generator wind turbines - The influence of rotor and speed controller parameters", Electrical Power and Energy Systems, 32, pp. 464-477 (2010).

21. Ackerman, T., Wind Power in Power Systems, 1st Ed., Wiely (2005).

22. Kundur, P., Power System Stability and Control, 2nd Ed., McGraw-Hill (1994).

\section{Appendix A}

Parameters of $660 \mathrm{~kW}, 690 \mathrm{~V}, 50 \mathrm{~Hz}$, LVS-WT:

$$
\begin{aligned}
& V_{\text {base }}=690 \mathrm{~V}, \quad S_{\text {base }}=660 \mathrm{KVA}, \quad f_{\text {base }}=50 \mathrm{~Hz}, \\
& I_{\text {base }}=552 \mathrm{~A}, \\
& \omega_{b}=2 \pi f_{b}=314 \mathrm{rad} / \mathrm{sec}, \quad R_{s}=0.00637 \mathrm{pu}, \\
& R_{r}=0.00596 \mathrm{pu},
\end{aligned}
$$

$$
\begin{aligned}
& L_{s}=2.93 \mathrm{pu}, \quad L_{r}=2.94 \mathrm{pu}, \quad L_{m}=2.88 \mathrm{pu}, \\
& H_{r}=0.54 \mathrm{sec}, \quad H_{t}=3.54 \mathrm{sec}, \quad D=1.2 \mathrm{pu}, \\
& k_{s h}=0.25 \mathrm{pu} / \text { elec. rad }, \quad n_{p}=2, \quad n_{\text {gear }}=52.7, \\
& \omega_{s}=1 \mathrm{pu}, \quad R_{e}=0.05 \mathrm{pu}, \quad L_{e}=0.1 \mathrm{pu},
\end{aligned}
$$

\section{Appendix B}

\section{Controller parameters used for the modal analysis and simulations:}

$$
\begin{aligned}
& k_{P-I_{r}}=0.214, \quad k_{I-I_{r}}=7.6, \\
& k_{P-P}=0.051, \quad k_{I-P}=31.4 .
\end{aligned}
$$

\section{Biography}

Mohsen Rahimi is an Assistant Professor at University of Kashan, Kashan, Iran. He received BSc degree in Electrical Engineering in 2001 from Isfahan University of Technology, Isfahan, Iran. He obtained both his MSc and PhD degrees in Electrical Engineering from Sharif University of Technology (SUT), Tehran, Iran in 2003 and 2011, respectively. Then, He worked for Saba Niroo, a wind turbine manufacturing company, during 2010-2011. His current research interests include modeling and control of power system dynamics with particular interest in control of grid-connected wind turbines and renewable energy sources. 